\title{
A NECESSIDADE DE PRODUZIR ALIENA A PAIXÃO DE CRIAR: REFLEXÕES ACERCA DA ARTE E DA EDUCAÇÃO NO SISTEMA CAPITALISTA
}

\author{
Talia Jeremias $^{1}$ \\ Rafael Rodrigo Mueller ${ }^{2}$ \\ Cristiano José Steinmetz ${ }^{3}$
}

Resumo: O presente estudo tem como objetivo estabelecer possíveis relações entre a pesquisa disponibilizada pela Associação Brasileira de Pesquisadores em Artes Plásticas (ANPAP) acerca dos cursos de artes em âmbito nacional, apresentada em matéria de Mirtes Martins de Oliveira na $39^{\circ}$ edição da Revista SeLecT, com alguns elementos do cenário brasileiro atual, tais como a Base Nacional Comum Curricular (BNCC), a Reforma do Ensino Médio e o projeto Escola Sem Partido. O processo metodológico de pesquisa considerou, sobretudo, as contribuições de Debord (2017) e outros situacionistas acerca da arte e da sociedade de modo geral, bem como as formulações de Dardot e Laval (2016) sobre a racionalidade neoliberal.

Palavras-chave: Arte. Educação. Sociedade do Espetáculo. Neoliberalismo.

\section{LA NECESIDAD DE PRODUCIR ALIENA LA PASIÓN DE CREAR: REFLEXIONES ACERCA DEL ARTE Y DE LA EDUCACIÓN EN EL SISTEMA CAPITALISTA}

Resumen: El presente estudio tiene como objetivo establecer posibles relaciones entre la investigación disponibilizada por la Asociación Brasileña de Investigadores en Artes Plásticas (ANPAP) acerca de los cursos de artes en ámbito nacional, presentada en materia de Mirtes Martins de Oliveira en la $39^{\circ}$ edición de la Revista SeLecT, con algunos elementos del escenario brasileño actual, tales como la Base Nacional Comum Curricular (BNCC), la Reforma do Ensino Médio y el proyecto Escola Sem Partido. El proceso metodológico de investigación consideró, sobre todo, las contribuciones de Debord (2017) y otros situacionistas acerca del arte y de la sociedad en general, así como las formulaciones de Dardot y Laval (2016) sobre la racionalidad neoliberal.

Palabras clave: Arte. Educación. Sociedad del espectáculo. Neoliberalismo.

\section{Introdução}

A Revista SeLecT, conhecida por atuar no campo da cultura e da arte contemporânea, lançou a sua $39^{\circ}$ edição em meados de 2018. Nela, uma matéria de

\footnotetext{
${ }^{1}$ Acadêmica do curso de Artes Visuais. Bolsista de Iniciação Cientifica -PIBIC/Unesc. Universidade do Extremo Sul Catarinense - UNESC; talia-jeremias@hotmail.com

${ }^{2}$ Doutor em Educação pela Universidade Federal de Santa Catarina. Professor do Programa de PósGraduação em Educação. Universidade do Extremo Sul Catarinense - UNESC; rrmueller@unesc.net

${ }^{3}$ Acadêmico do curso de Artes Visuais. Bolsista de Iniciação Cientifica -PIBIC/Unesc. Universidade do Extremo Sul Catarinense - UNESC; cjs18041993@gmail.com
}

Criar Educação, Criciúma, v. 8, no1, jan/jul 2019.- PPGE - UNESC 
Mirtes Martins de Oliveira ${ }^{4}$ apresentou uma dura e necessária discussão acerca dos rumos do ensino e da produção de arte no país, sinalizando algumas políticas neoliberais como possíveis engendradoras do quadro de precarização do campo artístico e educacional perceptível através do encerramento crescente de cursos de arte. A autora da matéria contou também com uma pesquisa realizada pela Associação Nacional dos Pesquisadores em Artes Plásticas (ANPAP), cujos dados revelam o encerramento da oferta de cursos de arte em diversos estados brasileiros, ilustrando um momento que poderia ser compreendido - em uma análise mais superficial - como uma crise da arte, portanto, um caso isolado dentro do mundo acadêmico. A pesquisa foi realizada com bases em dados de 2015 e 2016 de Instituições de Ensino Superior cadastradas no e-MEC, compondo uma lista de universidades públicas, privadas e comunitárias. Os dados demonstram que, em 2015, a descontinuidade ou fechamento total dos cursos de arte alcançaram $20 \%$ das licenciaturas e $28 \%$ de cursos de bacharelado, sejam eles presenciais ou a distância. Já em 2016, mais 17 cursos de arte entraram em processo de fechamento. Até o período, o total era de 52 cursos de arte em extinção no país.

Ao invés de particularizar, este texto se propõe a expandir a discussão iniciada pela Revista SeLecT, tendo como objetivo compreender não os dados em $\mathrm{si}$, mas a realidade e o conjunto das ações pautadas pela lógica neoliberal que incidem gravemente sobre o campo artístico e educacional. A proposta do texto não é, portanto, apresentar uma relação de causa e efeito para os dados, e sim realizar uma discussão acerca da conjuntura na qual esses dados se encontram. Logo, as mesmas questões que se originaram e, articuladamente, nortearam a matéria da Revista SeLecT também possibilitarão o desenvolvimento deste texto, a saber: a condição de fechamento de cursos e interrupção da oferta de vagas diz respeito apenas ao campo da arte, ou ao desmonte proposital do campo educacional? Quais as possibilidades dessa condição possuir alguma relação com projetos que visam perpetuar o ciclo de expansão do capital como a construção da Base Nacional Comum Curricular (BNCC) e a Reforma do Ensino Médio (Lei n 13.415/2017), além

\footnotetext{
${ }^{4}$ OLIVEIRA, Mirtes Martins de. Enterradas vivas: estratégias neoliberais. Revista SeLecT, $\mathrm{N}^{\circ}$ 39, junho de 2018. Disponível em: http://premio-select.com.br/enterradas-vivas-estrategias-neoliberais/
}

Criar Educação, Criciúma, v. 8, no1, jan/jul 2019.- PPGE - UNESC 
da crescente onda de conservadorismo incentivada por movimentos como Escola Sem Partido?

Sobretudo, mais do que uma denúncia acerca do desmonte educacional e cultural tanto no nível básico quanto no nível superior de ensino, este texto faz a defesa de uma formação cujo princípio seja o desenvolvimento de "relações capazes de criar zonas de liberdade onde a existência possa se libertar dos ditames da mercadoria, banindo a competição em nome da emulação e o trabalho em nome da criatividade" (VANEIGEM, 2016, p. 21), que compreenda a arte como uma necessidade para a vida e que contraponha um projeto de educação cuja dimensão verdadeiramente formativa está sendo paulatinamente destruída.

\section{Espetáculo, neoliberalismo e a busca enganosa por liberdade}

As facetas e os mecanismos de coação da sociedade espetacular foram radicalmente expostos numa das obras mais importantes da formulação marxista sobre a sociedade capitalista moderna: A Sociedade do espetáculo (1967), propositalmente esquecida por aqueles que ela critica. Guy Debord, o autor, talvez tenha sido uma das pouquíssimas pessoas que conseguiu enxergar com clareza uma sociedade da qual os mecanismos de dominação trabalham sistematicamente para que os sujeitos não a enxerguem de verdade.

$\mathrm{Na}$ forma de aforismos, Debord tentou nos alertar sobre o aperfeiçoamento das condições de alienação e governabilidade dos sujeitos decorrentes do próprio desenvolvimento do sistema capitalista - o espetáculo - que, "como inversão concreta da vida, é o movimento autônomo do não vivo" (DEBORD, 2017, p. 37, grifos nossos), ou seja, é a negação dos próprios sujeitos em prol da afirmação das mercadorias que dominam a vida social. Em síntese, o espetáculo é o devir imagem da mercadoria, o momento visível do avanço da dominação das coisas sobre os seres humanos, marcado pela alienação e passividade na contemplação das mercadorias e pela perda da consciência dos desejos e necessidades reais dos indivíduos.

Além das teses apresentadas na primeira publicação do livro, é preciso nos atentarmos também para as pistas deixadas por Debord nos Comentários sobre a sociedade do espetáculo (1988). Lá, tem-se que

Criar Educação, Criciúma, v. 8, no1, jan/jul 2019.- PPGE - UNESC 


\section{CRIAR EDUCAÇÃOO}

Revista do Programa de Pós-Graduação em Educação - UNESC

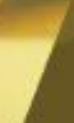

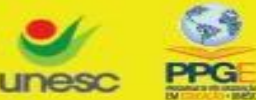

Unahoe:

unesc

a mudança de maior importância, em tudo o que aconteceu há vinte anos, reside na própria continuidade do espetáculo. Essa importância não decorre do aperfeiçoamento de sua instrumentação midiática, que já havia atingido um estágio de desenvolvimento muito avançado; decorre do fato de a dominação espetacular ter podido educar uma geração submissa a suas leis (DEBORD, 2017, p. 195, grifos nossos).

Nesse sentido, é possível dizer que a sociedade espetacular é marcada por uma racionalidade - "uma Weltanschuung que se tornou efetiva, materialmente traduzida" (DEBORD, 2017, p. 38) - instituída propositalmente, como forma de perpetuar o alcance e a expansão do capital.

Tendo isso em perspectiva, para compreendermos a condição atual do ensino e da produção de arte, cabe-nos pensar de que modo a educação e a formação dos indivíduos ainda hoje colaboram com o movimento de espetacularização da vida social. Talvez a maneira mais clara de compreender como educação e formação podem estar articuladas com o movimento de expansão do espetáculo seja por meio do manifesto A Miséria do Meio EstudantiF, publicado em novembro de 1966 pela Internacional Situacionista.

De forma mais abrangente, A Miséria visava denunciar de forma radical a pseudoliberdade oferecida aos estudantes na França que, em razão da sua formação voltada estritamente para a inserção no mercado de trabalho de maneira a produzir e reproduzir a alienação, não passavam de engrenagens no mecanismo de funcionamento da máquina capitalista. É por isso que, para os situacionistas, as "exigências do capitalismo moderno fazem com que a maioria dos estudantes acabem conseguindo ser apenas pequenos funcionários" (I.S., 2002, p. 33, grifos nossos), de tal modo que o espetáculo pode vangloriar-se por ter "[...] feito do direito ao trabalho, isto é, à escravidão assalariada, a reivindicação social central" (I.S., 2002, p. 28). A Miséria, além de criticar a dominação do sistema vigente, também não poupa críticas irônicas aos próprios estudantes que, frente um futuro incerto -

\footnotetext{
${ }^{5}$ Apesar de sua publicação se dar através da Internacional Situacionista, a autoria é de Mustapha Khayati, que permaneceu na I.S. até aproximadamente 1970. O manifesto foi um pedido de estudantes da Universidade de Strasbourg que almejavam destruir o diretório acadêmico. A estratégia situacionista para a destruição foi produzir 10 mil exemplares do manifesto em uma edição de luxo, o que acabou minando as finanças do diretório. Fizeram parte da I.S.: Guy Debord, Raoul Vaneigem, Mustapha Khayati, Asger Jorn, Michèle Bernstein, entre outros. Ver INTERNACIONAL SITUACIONISTA, Situacionista: teoria e prática da revolução. São Paulo: Conrad Editora do Brasil, 2002.
}

Criar Educação, Criciúma, v. 8, no1, jan/jul 2019.- PPGE - UNESC 
já que o sistema econômico capitalista é complexo e imprevisível -, encaram o presente e alimentam ilusões de que esse mesmo sistema instável lhes garantirá as condições do sucesso pessoal. Entretanto, para os situacionistas, os estudantes ignoram que até mesmo os seus desejos e os seus sonhos são governados pelo sistema. Criados para alimentar tal presente "vivido de modo irreal", "esses sonhos de hoje não passam, na realidade, dos pesadelos de amanhã" (I.S., 2002, p. 29). Como visto, uma geração inteira pode ser capturada no processo de autoafirmação do espetáculo, reduzindo-se em mero suporte para a circulação de imagensmercadorias que possibilitam um cotidiano alienado e alienante.

Em função disto, torna-se desnecessário e até mesmo ingênuo questionarmos os motivos pelos quais uma sociedade aparentemente crítica e politizada permite que a educação e formação dos seus indivíduos se constitua em tamanha miséria. Por mais habitual e supostamente ousado que seja vincular educação à termos como 'liberdade', 'emancipação' e 'pensamento crítico', percebese que, em uma sociedade governada sob as amarras do espetáculo, o sistema objetiva apenas sua autovalorização. Daí a necessidade de se instaurar na educação a lógica de produção de "pequenos funcionários", como bem apontaram os situacionistas ainda na década de 60 . Para tanto, o sistema não permite nada que intimide o seu funcionamento e, consequentemente, a realização de toda crítica essencialmente radical e negativa é posta à margem.

Marcuse (2016, p. 42), por exemplo, nos diz que a

independência de pensamento, autonomia e o direito de oposição política estão sendo privados de sua função essencialmente crítica em uma sociedade que parece crescentemente capaz de satisfazer as necessidades dos indivíduos por meio da forma como está organizada. Tal sociedade pode, justamente, exigir a aceitação de seus princípios e instituições e reduzir a oposição à discussão e promoção de alternativas políticas dentro do status quo.

Portanto, se algo - o pensamento negativo - ameaça o bom funcionamento da máquina capitalista, ele é apropriado pelo próprio sistema, que o esvazia de sua negatividade e o torna raso de modo a servir-se dele para criticar os seus próprios excessos, tomando o cuidado de nunca expor a raiz da sua dominação. Nesse sentido, a sociedade capitalista se releva uma sociedade positivada, responsável por destituir a crítica enquanto negatividade e torná-la complacente ao fluxo daquilo que Criar Educação, Criciúma, v. 8, no1, jan/jul 2019.- PPGE - UNESC 
governa os sujeitos - o capital. Em vista disso, como visto anteriormente, se a sociedade positivada precisa criar mecanismos para impossibilitar a oposição à dominação do sistema sobre os sujeitos, todos os setores da sociedade precisam estar, justamente, sob o seu domínio e dela decorrerem — inclusive a educação e a formação dos sujeitos.

Consequentemente, se a educação em sua totalidade pode ser verdadeiramente livre, emancipatória e crítica, o espetáculo poderá tomar todas as precauções para que essa oposição não seja tão revolucionária assim. O senso comum, novamente, afirma que a educação pode conter a chave para "libertar" os sujeitos perante uma opressão qualquer. A positividade, embora enalteça a natureza pseudo-crítica da educação, não nos fornece pistas suficientes para apontar a origem dessa opressão, de tal maneira que ela pode surgir pela alienação produzida pelos meios de comunicação de massa ou por um poder doutrinador, por exemplo. Isso decorre do fato de que a sociedade positivada, caracterizada pelo domínio da crítica não dialética, organiza a própria crítica ao sistema do qual ela é parte fundamental. Desse modo, a "discussão vazia sobre o espetáculo — isto é, sobre o que fazem os donos do mundo - é organizada pelo próprio espetáculo: destacamse os grandes recursos do espetáculo, a fim de não dizer nada sobre seu uso" (DEBORD, 2017, p. 194).

Assim, a educação pode funcionar como uma ferramenta ideológica utilizada pelo espetáculo para a produção dos "pequenos funcionários", que se dá através da instituição de uma determinada racionalidade positivada, espetacular. Em outras palavras, "a nova normatividade das sociedades capitalistas impôs-se por uma normatização subjetiva de um tipo particular (DARDOT e LAVAL, 2016, p. 324, grifos nossos). Aqui, tal racionalidade apresenta-se como uma possibilidade de liberdade em relação ao sistema mercantil na figura do sujeito neoliberal, ensinado a governar a si mesmo como uma empresa, a maximizar os seus lucros e a expandir a valorização do seu capital humano. A fabricação desse sujeito passa por um processo de transformação da subjetividade, de tal modo que ele se entregue completa e objetivamente ao trabalho, uma vez que 
anima o "colaborador" da empresa, enfim, o desejo com todos os nomes que se queira dar a ele é o alvo do novo poder (DARDOT e LAVAL, 2016, p. 327 , grifos nossos).

De forma semelhante aos situacionistas, Dardot e Laval (2016) parecem nos alertar sobre uma formação na qual os sonhos dos indivíduos - o projeto de vida é governado pelo próprio sistema. Tal dominação é travestida de um sentimento de "liberdade individual" que incentiva a competição e a concorrência por um lugar ao sol do sistema capitalista.

Byung-Chul Han também trata dessa questão quando diz que

\begin{abstract}
cremos hoje que não somos um sujeito submetido, mas um projeto livre, que se repõe em questão e reinventa constantemente. Essa passagem do sujeito ao projeto é acompanhada pelo sentimento de liberdade. Ora, acontece que o próprio projeto se revela como uma figura de coação, ou até mesmo como uma forma eficaz de subjetivação e de submissão. O eu como projeto que crê ter-se libertado das coações externas e das coerções alheias, submete-se a coações internas e coerções próprias sob a forma de uma coação ao rendimento e à otimização (HAN, 2015, p. 11).
\end{abstract}

Isso significa, portanto, que o sujeito, em sua pseudoliberdade, é livre para entregar-se de corpo e alma a função exercida e livre para render o máximo de lucro. O sujeito neoliberal é medido pela sua eficiência, de tal modo que o seu sucesso pessoal depende unicamente do resultado do seu trabalho. Consequentemente, ao se enxergar alienadamente na função realizada, o sujeito neoliberal afasta-se de si mesmo. Debord parece atentar para isso quando diz que "quanto mais sua vida se torna seu produto, tanto mais ele se separa da vida" (DEBORD, 2017, p. 49, grifos nossos).

O neoliberalismo, portanto, é uma racionalidade que faz crer na liberdade individual enquanto uma maneira de fugir do sistema que anteriormente oprimia. No entanto, tanto Byung-Chul Han (2015) quanto Dardot e Laval (2016) deixam claro que não existe mais um sistema que domina e explora diretamente os sujeitos pois essa condição já não é mais útil ao capital. Como apontado anteriormente, é preciso instituir uma determinada racionalidade na qual os sujeitos passem a ser os senhores de si, isto é, passem a se autogovernar. É preciso, portanto, "educar uma geração submissa a suas leis" (DEBORD, 2017, p. 195), porém, agora, os próprios sujeitos as perpetuam. 
Se o espetáculo se serve da educação para os seus fins, esta educação tem como intuito, portanto, possibilitar a fabricação de homens úteis que entendem a si mesmos como empresa e empresário de si próprios. A personalidade do sujeito precisa ser moldada de forma a adequar-se ao movimento do sistema mercantil, produzindo e reproduzindo a lógica de que a educação deve formar um estudante que "desempenha um papel provisório, que o prepara para o papel definitivo que irá assumir, como elemento positivo e conservador, dentro do funcionamento do sistema mercantil. É apenas uma iniciação, e nada mais que isso" (I.S., 2002, p. 32).

Mesmo mais de meio século depois, se o manifesto situacionista ainda nos parece terrivelmente atual, é porque as condições nas quais são pensadas o processo formativo dos sujeitos e a organização da sociedade no geral ainda se mantém as mesmas, até mais aperfeiçoadas e naturalizadas do que antes. Nas últimas décadas, sobretudo com o processo de redemocratização, o Brasil tem sido alvo de projetos liderados pelo campo empresarial voltados para a manutenção da educação básica e do ensino superior justamente sob a ótica da produção de sujeitos economicamente ativos, incentivando o "empreendedorismo", o "protagonismo juvenil" e o "governo de si", tal qual a denúncia dos situacionistas.

Entre os documentos normativos para a educação básica, podemos citar a Base Nacional Comum Curricular (BNCC) que propõe que a educação, sobretudo o Ensino Médio, seja voltada para o desenvolvimento de competências, definidas pelo próprio documento como a

[...] mobilização de conhecimentos (conceitos e procedimentos), habilidades (práticas, cognitivas e socioemocionais), atitudes e valores para resolver demandas complexas da vida cotidiana, do pleno exercício da cidadania e do mundo do trabalho (BRASIL, 2018, p. 8, grifos nossos).

Segundo a BNCC, uma das dez competências gerais para a educação básica é

valorizar a diversidade de saberes e vivências culturais e apropriar-se de conhecimentos e experiências que the possibilitem entender as relações próprias do mundo do trabalho e fazer escolhas alinhadas ao exercício da cidadania e ao seu projeto de vida, com liberdade, autonomia, consciência crítica e responsabilidade (BRASIL, 2018, p. 9, grifos nossos).

Assim, a estrutura do currículo escolar deve estar organizada de tal modo que todas as áreas girem em torno dessas dez competências e habilidades que 0 
que, por sua vez, reproduzirão, ampliarão e reforçarão as relações de competição entre eles, o que exigirá, segundo a lógica do processo autorrealizador, que eles se adaptem subjetivamente às condições cada vez mais duras que eles mesmos produziram (DARDOT e LAVAL, 2016, p. 329 os grifos são meus).

Além disso, nesse ponto da discussão já é possível perceber que o espetáculo, sendo aquele que "não diz nada além de "o que aparece é bom, o que é bom aparece"” (DEBORD, 2017, p. 40-41), impossibilitando a existência de tudo aquilo que foge à lógica da positividade, produtividade e rendimento, nega o caráter de formação humana das instâncias da vida social como, por exemplo, a da arte. Tudo aquilo que não tem utilidade imediata para o sistema permanece fora do mundo visível. Com relação à arte, é fundamental comentar outra mudança recente no cenário educacional brasileiro que colabora para a produção da racionalidade neoliberal encontrada na BNCC: a Lei no 13.415/2017 - a "Reforma do Ensino Médio" - que, ao alterar a Lei de Diretrizes e Bases da Educação Nacional (LDB), propõe uma mudança no que diz respeito a organização de um currículo escolar mais flexível, considerando as demandas do mundo do trabalho. Uma vez que a BNCC para o Ensino Médio prevê a obrigatoriedade apenas da língua portuguesa e da matemática nos três anos do processo formativo, as outras áreas do conhecimento que anteriormente compunham o currículo escolar são divididas em "itinerários formativos" e são concebidas de forma utilitária, isto é, devem servir para o desenvolvimento das competências e habilidades propostas para os estudantes novamente, o saber e o saber fazer -, já que serão atribuídas às áreas do conhecimento determinadas funções e, consequentemente, determinados usos.

Nessa nova condição, a arte é realocada no currículo como uma linguagem utilitária, ocasionando na instrumentalização dos seus processos pedagógicos e formativos, uma vez que deverá ser capaz de desenvolver habilidades e competências. Produz-se um discurso que destaca palavras-chave como "reflexão", "expressão", "criatividade" e "emoção" — que são, de fato, importantes no âmbito da arte, mas não representam a totalidade da dimensão artística e cultural - e as situa no processo de produtividade para o fim último, que diz respeito à capacitação dos sujeitos para a sua atuação nas condições de vida existentes. 


\title{
(1)

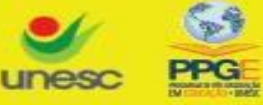

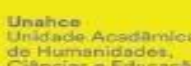

Não obstante, a "escola que acolhe as juventudes" apontada no documento da BNCC deve ser estruturada de tal modo que as áreas do conhecimento e suas respectivas competências e habilidades sejam capazes de, entre outras atribuições,

proporcionar uma cultura favorável ao desenvolvimento de atitudes, capacidades e valores que promovam o empreendedorismo (criatividade, inovação, organização, planejamento, responsabilidade, liderança, colaboração, visão de futuro, assunção de riscos, resiliência e curiosidade científica, entre outros), entendido como competência essencial ao desenvolvimento pessoal, à cidadania ativa, à inclusão social e à empregabilidade (BRASIL, 2018, p. 466, grifos nossos).

Similarmente, a educação também deve

\begin{abstract}
prever o suporte aos jovens para que reconheçam suas potencialidades e vocações, identifiquem perspectivas e possibilidades, construam aspirações e metas de formação e inserção profissional presentes e/ou futuras, e desenvolvam uma postura empreendedora, ética e responsável para transitar no mundo do trabalho e na sociedade em geral (BRASIL, 2018, p. 466, grifos nossos).
\end{abstract}

Como mencionado anteriormente, o enaltecimento de termos como "valores", "inovação", "eficiência”, "responsabilidade", "confiança", "autoestima”, entre outros tão recorrentes no documento da BNCC, são parte fundamental do processo de formação da racionalidade neoliberal, como salientam Dardot e Laval (2016). A importância desse processo se dá na aparência de que a máxima eficácia do indivíduo - o estudante, nesse caso - não é incentivada em favor da profissionalização precoce e da manutenção do mercado de trabalho, mas sim em defesa da melhora do desempenho do indivíduo e da realização pessoal na figura de um projeto de vida - o sonho administrado.

Afinal, na organização vigente da sociedade, o interesse hegemônico se volta para o lucro imediato e a manutenção e contenção da constante crise econômica através da produção de sujeitos eficazes e produtivos, tendo em vista que

o indivíduo que foi marcado pelo pensamento espetacular empobrecido,
mais do que por qualquer outro elemento de sua formação, coloca-se de
antemão a serviço da ordem estabelecida, embora sua intenção subjetiva
possa ser o oposto disso. Nos pontos essenciais, ele obedecerá à
linguagem do espetáculo, a única que conhece, aquela que lhe ensinaram a
falar. (DEBORD, 2017, p. 214).

Além disso, com mecanismos que operam sistematicamente para a veiculação da coação e do medo, é compreensível que os sujeitos deem preferência ao que supostamente lhes oferece minimamente estabilidade financeira para a Criar Educação, Criciúma, v. 8, no1, jan/jul 2019.- PPGE - UNESC 
garantia da subsistência visto a perene instabilidade do modo de produção e reprodução da vida social no capitalismo que, "enquanto liberdade para trabalhar ou morrer de fome, [...] significa labuta, insegurança e medo para uma grande maioria da população" (MARCUSE, 2016, p. 42).

Nesse sentido, a frase que dá título ao artigo retoma o seu sentido: a necessidade de produzir aliena a paixão de criar, afinal

\begin{abstract}
o que sobra de centelha humana, de criatividade possível, em um ser arrancado do sono às $6 \mathrm{~h}$ da manhã, sacudido nos trens suburbanos, ensurdecido pelo barulho das máquinas, lixiviado e vaporizado pelas cadências, pelos gestos sem sentido, pelo controle estático, e empurrado no fim do dia para os saguões das estações [...] quando a multidão comunga na fadiga e no embrutecimento? (VANEIGEM, 2016 p. 69, grifos nossos).
\end{abstract}

Ou seja: como é possível fruir e produzir arte quando se há a necessidade de se coisificar e se autogovernar para garantir um lugar na luta de todos contra todos na selva de pedras reluzentes do capitalismo? As chances são poucas, a não ser que a arte seja considerada "entretenimento", sem nenhum teor crítico.

$\mathrm{Na}$ sociedade da produtividade, a arte é destituída de seu caráter formativo e humano - e, consequentemente, livre - para servir ao processo alienado e alienante de produção e reprodução capitalista. O processo de fruição em todos os seus sentidos é comprometido e, consequentemente, compromete-se também a satisfação das "necessidades provenientes da imaginação", uma vez que os indivíduos, impossibilitados de viver humanamente por causa do trabalho alienado, não têm acesso à totalidade da arte e da sua produção historicamente construída, muito menos de realizar a arte na vida como um trabalho livre e dela fazer uso. Desse modo, a função social da arte é redimensionada para o campo da produção e reprodução do sistema vigente, onde ela se torna "incapaz de conter as riquezas possíveis da vida humana" (JAPPE, 2013, p. 228), ignorando que "as produções culturais fazem parte da esfera simbólica, dessas estruturas com as quais os homens sempre tentaram representar e explicar a si mesmos a vida e a sociedade, e por vezes também criticá-las" (JAPPE, 2013, p. 231). É nesse sentido que Debord e os situacionistas anunciam o fim da arte: quando ela é transformada em mercadoria espetacular, perde-se o seu caráter crítico e, consequentemente, a sua realização. 
Nessa perspectiva, é importante salientar que o processo de legitimação de um sistema autocrático e de instauração de uma racionalidade espetacular pode passar, sobretudo, pela negação e/ou pela inversão de determinadas narrativas "o fim da história é um agradável repouso para todo poder presente" (DEBORD, 2017, p. 201). Sendo o dono do monopólio do discurso, o sistema se utiliza de instrumentos coercitivos intentando a destruição de parte do conhecimento e consciência histórica para que a própria história recente do espetáculo permaneça desconhecida, assim, "seu poder já soa familiar, como se sempre tivesse estado presente. Qualquer usurpador tenta fazer esquecer que acabou de chegar" (DEBORD, 2017, p. 202).

Nos Comentários sobre a sociedade do espetáculo, Debord (2017) nos fala sobre a "mentira sem contestação", característica do espetáculo integrado — avanço do espetáculo em relação as suas formas anteriores -, que transforma a própria verdade e o conhecimento histórico em hipóteses marginais. Como já mencionado, o pensamento positivado submisso ao sistema trabalha constantemente no sentido de retirar o caráter revolucionário das narrativas sem possibilitar espaço para uma oposição verdadeira. A memória, portanto, que deveria ser usada para compreender os movimentos da novidade, agora é reprimida e usada para justificar os movimentos dessa mesma novidade, isto é, o sistema inverte a própria história a fim de efetivar a sua manutenção e afirmar a si mesmo como o único detentor da "verdade". Nessa perspectiva, o esquecimento, fruto da destruição da história, confere ao poder presente todas as bases materiais e ideológicas para a criação das suas verdades e das suas mentiras de acordo com seus interesses e necessidades. Impossibilitados de sua consciência histórica - e até mesmo do desejo dela - os indivíduos permanecem submissos ao poder do sistema, pois agora "a história se apresenta aos homens como um fator estranho, como aquilo que eles não quiseram e aquilo contra o que eles pensavam estar protegidos" (DEBORD, 2017, p. 113).

Voltando-nos novamente para o contexto nacional, além da construção de uma série de reformas e projetos impulsionados por interesses empresariais de produção e reprodução de uma racionalidade neoliberal como a Base Nacional 
Comum Curricular (BNCC) e a Reforma do Ensino Médio, um espectro ronda a conjuntura educacional brasileira - o espectro do projeto Escola Sem Partido.

Apesar de já ter sido considerado inconstitucional, tal projeto tem dois aspectos principais que precisam ser observados com cuidado. O primeiro diz respeito ao fato de que o Escola Sem Partido reforça a instrumentalização dos processos formativos e pedagógicos, uma vez que a escola deve apenas formar para o trabalho, produzindo, novamente, um ensino básico que redimensionará ainda mais a formação dos indivíduos no sentido da deformação, caracterizada pela concepção do "ser humano como personificação do capital, de um lado, e, de outro, como personificação do trabalho - mero portador de força de trabalho (ANTUNES, 2016, p. 105, grifos nossos).

Penna, ao analisar os discursos em defesa do projeto, diz que

o movimento Escola Sem Partido defende que apenas a família e a religião podem educar, e os professores devem se restringir a instruir os alunos com o único objetivo de qualificá-los para o mercado de trabalho. Tal assertiva qualifica o projeto como uma iniciativa que busca destruir o caráter educacional da escola e da sala de aula como espaço de debate e aprendizado para a vida (PENNA, 2018, p. 111, grifos nossos).

O segundo aspecto diz respeito ao fato de que o projeto lançou sobre o país a pseudonecessidade de perseguir "inimigos ideológicos" encontrados nas figuras dos professores, sobretudo aqueles inseridos nos campos das ciências humanas e sociais. O "Escola Sem Partido", impulsionado desde 2004, define-se como um projeto contrário à propaganda partidária em sala de aula, mas tem como pano de fundo a necessidade de se instituir na educação a construção de uma narrativa antidemocrática, visando a proibição de determinados assuntos que entram em conflito direto e/ou indireto com questões morais e religiosas. Destituindo a educação de toda crítica, é perceptível o caráter conservador muito influente no projeto, marcado pela negação de determinadas narrativas e pelo revisionismo histórico, sobretudo no que tange a história recente do país.

Esse ponto é de extrema relevância, pois

com a destruição da história, o próprio acontecimento contemporâneo logo se afasta para uma distância fabulosa, em meio a narrativas inverificáveis, estatísticas incontroláveis, explicações inverossímeis e raciocínios insustentáveis (DEBORD, 2017, p. 202). 
Ao instituir na educação a instrumentalização do conhecimento, uma narrativa antidemocrática e o redimensionamento unilateral para o trabalho alienado, não se produz uma formação livre de doutrinações, ao contrário do que o Escola Sem Partido reproduz com tanto fervor. Produz-se, na verdade, uma escola unipartidária, isto é, uma escola politicamente inclinada às demandas das condições socioeconômicas pré-estabelecidas, impossibilitando toda e qualquer oposição ou toda e qualquer realidade que fuja daquela pautada na condição de governo e otimização de si. Portanto, a escola unipartidária contribui para a unilateralidade do sistema capitalista ao cercear as possibilidades formativas dos estudantes, uma vez que a totalidade da dimensão educacional se volta estritamente para o campo visível da luta entre capitais humanos.

O espetáculo é o momento em que a mercadoria ocupou totalmente a vida social. Não apenas a relação com a mercadoria é visível, mas não se consegue ver nada além dela: o mundo que se vê é o seu mundo (DEBORD, 2017, p. 54).

Por isso, a impossibilidade de difusão do ensino e da produção de arte não se apresenta somente enquanto um reflexo do sistema mercantil-concorrencial do neoliberalismo, mas também como um meio de negação daquilo que, em sua essência, procura confrontar o poder do sistema dominante. No entanto, apesar de apontar a cultura e a arte como objetos mortos que reforçam o poder de classes quando são mercantilizadas e consideradas categorias separadas da vida social, Debord vê em ambas uma possibilidade de crítica social e reestabelecimento de uma linguagem comum encontrada na práxis, bem como a própria negação da sociedade capitalista.

$\mathrm{Na}$ linguagem da contradição, a crítica da cultura se apresenta unificada: porque domina toda a cultura - seu conhecimento e sua poesia - e porque ela já não se separa da crítica da totalidade social. É essa crítica teórica unificada, e apenas ela, que vai ao encontro da prática social unificada (DEBORD, 2017, p. 159).

Debord também diz que

A cultura provém da história que dissolveu o gênero de vida do velho mundo. Mas, como esfera separada, ela é tão somente a inteligência e a comunicação sensível que continuam parciais numa sociedade parcialmente histórica. Ela é o juízo de um mundo pouquíssimo capaz de julgar (DEBORD, 2017, p. 145). 
Não é preciso enfatizar que "tornar-se mais simpática à sociedade" é colaborar com a produção da subjetividade neoliberal e que "ser útil" e "agradar" é justamente destituir-se de toda crítica essencialmente negativa para tornar-se uma mercadoria na sociedade positiva, isto é, um objeto morto.

\section{Considerações finais}

Tendo em vista esse horizonte, parece-nos que o projeto vigente para a educação é justamente o seu desmonte, considerando as condições atuais de produção de um ensino extremamente básico pautado em saberes instrumentais necessários para a inserção no mercado de trabalho (sem direitos ou garantias, tendo em vista o prelúdio do cenário político e econômico nos próximos anos), que possibilite apenas a garantia da sobrevivência. Todas as condições nas quais se encontram o campo artístico e educacional atualmente dizem respeito não a um problema restrito da área, mas à lógica mercantil-concorrencial da qual os indivíduos não podem escapar. Esta é a única condição posta: ou permanecer em sintonia com o movimento espetacular do capital ou desaparecer.

Como também apontou a matéria anteriormente citada, em uma sociedade cuja lógica máxima é a do lucro imediato, a educação e o ensino - como todas as outras instâncias da vida social - são consideradas mercadorias e os sujeitos, consequentemente, consumidores. Nessa perspectiva, os dados denunciados pela Revista SeLecT se tornam mais "transparentes" quando relacionados ao contexto econômico, político e social vivenciado. A arte e a cultura, se não oferecerem resultados imediatos em prol do crescimento da economia e redução de sua instabilidade - tanto como produção de sujeitos eficazes quanto como "entretenimento" e "diversão" - , de nada valem para o sistema econômico vigente, afinal, este "[...] não deseja chegar a nada que não seja ele mesmo" (DEBORD, 2017, p. 41, grifos nossos).

Percebe-se, então, que os cursos de arte em processo de fechamento dizem respeito à um processo que vai além de uma crise interna. Os dados apresentados são parte da condição imposta ao campo da educação e da arte pelo neoliberalismo. Além disso, ao retirar a obrigatoriedade da arte do currículo escolar e possibilitar a sua não oferta no restante do processo formativo, ao instrumentalizá-la e Criar Educação, Criciúma, v. 8, no1, jan/jul 2019.- PPGE - UNESC 
mercantilizá-la, poder-se-á acarretar no cerceamento do campo artístico nas universidades, como a Associação Nacional dos Pesquisadores em Artes Plásticas (ANPAP) demonstrou estar ocorrendo desde 2015 - e, cabe ressaltar, não apenas do campo artístico, mas a tendência é que a própria universidade sofra um processo ainda maior de elitização e despolitização em todos os âmbitos.

Entretanto, uma coisa é fundamental: não basta apenas garantir a oferta do ensino da arte nas escolas e nas universidades. Os situacionistas já nos disseram que "a inversão da perspectiva não pode, de maneira nenhuma, passar pelas soluções que já foram, há muito, previstas pelo próprio sistema: "a integração", "o trabalho para todos", "a reforma da educação' e outras garantias da seguridade social” (I.S., 2002, p. 29). É preciso reinventar a educação, bem como toda a organização social que a rege.

Marcuse (2016), tratando da lógica neoliberal da liberdade individual e governo de si mesmo discutidos ao longo desse texto, diz que

\begin{abstract}
se o indivíduo já não fosse mais forçado a ser bem-sucedido no mercado, como um sujeito economicamente livre, o desaparecimento desse tipo de liberdade seria uma das maiores realizações da civilização. Os processos tecnológicos de automação e estandardização podem liberar energia individual para um reino ainda desconhecido de liberdade, situado para além da necessidade. A própria estrutura da existência humana seria alterada; o indivíduo seria liberado do mundo do trabalho que impõe a ele necessidades e possibilidades que lhe são estranhas. O indivíduo seria livre para exercer a autonomia sobre uma vida que seria propriamente sua (MARCUSE, 2016, p. 42, grifos nossos).
\end{abstract}

A educação enquanto formação humana só parece possível em um mundo emancipado, livre das amarras do capitalismo e onde as capacidades e habilidades humanas não sejam convertidas na mera capacitação para a submissão ao trabalho alienado. A educação, se quiser ser verdadeiramente crítica e formativa, deverá se colocar como um elemento negativo no modo de vida existente, ou seja, a educação deve pautar a recusa profunda do espetáculo e sua dominação. O mesmo pode ser dito sobre a arte.

De acordo com Jappe (2013, p. 237),

poderíamos dizer da arte o mesmo que vale para a ética: ela estabelece parâmetros, indica até onde os indivíduos devem forçar-se a chegar - e não o contrário. Uma das funções sociais da arte sempre foi mostrar aos indivíduos um mundo superior, onde se encontram a liberdade e a 
intensidade cuja ausência se fazia tão cruelmente sentir na vida de todos os dias.

Tal função social - de mostrar um "mundo superior" aos indivíduos - é destruída quando a arte é instrumentalizada e mercantilizada. Se o espetáculo "[...] não deseja chegar a nada que não seja ele mesmo" (DEBORD, 2017, p. 41) e o seu fim é um presente perpétuo no qual o seu reino autocrático nunca cessa, que "mundo superior" a arte poderia ser capaz de oferecer?

Por essa razão que, mais do que garantir a possibilidade de uma formação em arte, seja no nível básico, no nível superior ou na própria vida cotidiana, é preciso repensar a função social da arte e de sua realização - bem como da própria educação. Há mais de 50 anos, os situacionistas nos deixaram algumas pistas: a realização efetiva da arte só ocorrerá se passar pela recusa radical do modo de vida existente, pela recusa da contemplação passiva frente às mercadorias, pela reinvenção de outra temporalidade que não aquela da produtividade, pela sua afirmação como conhecimento histórico e pelo seu uso na vida cotidiana. Podemos dizer, como os situacionistas antes de nós, que enquanto a arte continuar articulada aos ditames do sistema mercantil, ela continuará morta.

\section{Referências}

ANTUNES, Caio Sgarbi. A escola do trabalho: formação humana em Marx. 2016. 184 f. Tese (Doutorado) - Curso de Educação da Faculdade de Educação, Universidade Estadual de Campinas, Campinas, 2016.

BRASIL. Ministério da Educação. Base Nacional Comum Curricular. Disponível em: http://basenacionalcomum.mec.gov.br, 2016. Acesso em 25 fev. 2019.

BOLTANSKI, Luc; CHIAPELLO, Éve. O novo espírito do capitalismo. São Paulo: WMF Martins Fontes, 2009.

DEBORD, Guy. A sociedade do espetáculo: 50 anos depois, mais atual que nunca. 2 ed. Rio de Janeiro: Contraponto, 2017264 p.

HAN, Byung-Chul. Psicopolítica: neoliberalismo e novas técnicas de poder. Lisboa: Relógio D'Água Editores, 2015. 92 p.

INTERNACIONAL SITUACIONISTA. Situacionista: teoria e prática da revolução. São Paulo: Conrad Editora do Brasil, 2002. Coleção Baderna. 


\section{CRIAR EDUCAÇÃO}

Revista do Programa de Pós-Graduação em Educação - UNESC

JAPPE, Anselm. Crédito à morte: A decomposição do capitalismo e suas críticas.

São Paulo: Hedra, 2013. 242 p.

LAVAL, Christian; DARDOT, Pierre. A nova razão do mundo: ensaio sobre a sociedade neoliberal. São Paulo: Boitempo, 2016. 413 p.

MARCUSE, Herbert. O homem unidimensional: estudos da ideologia da sociedade industrial avançada. São Paulo: Edipro, 2015. 245 p.

PENNA, Fernando. O discurso reacionário de defesa de uma "escola sem partido". In: GALLEGO, Esther Solano (Org.). 0 ódio como política: A reinvenção das direitas no Brasil. São Paulo: Boitempo, 2018. p. 109-114.

VANEIGEM, Raoul. A arte de viver para as novas gerações. São Paulo: Veneta, 2016. 352 p. 